\title{
Ectopic Sebaceous Glands in the Esophagus: Endoscopic Findings over Three Years
}

\author{
Minoru Fukuchi $^{\mathrm{a}} \quad$ Ritsuko Tsukagoshi $^{\mathrm{a}}$ Shinji Sakurai ${ }^{\mathrm{b}}$ \\ Shinsuke Kiriyama ${ }^{a}$ Katsuhiko Horiuchi $^{\mathrm{C}}$ Kazuhisa Yuasa $^{\mathrm{c}}$

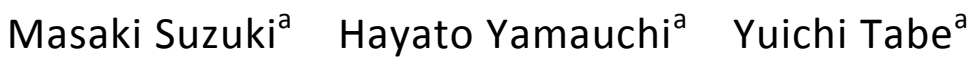 \\ Takaharu Fukasawa $^{a}$ Hiroshi Naitoh $^{a}$ Hiroyuki Kuwano $^{d}$ \\ Departments of a Surgery, ${ }^{\mathrm{b}}$ Diagnostic Pathology and ${ }^{\mathrm{c}}$ Gastroenterology, Social \\ Insurance Gunma Chuo General Hospital, and ${ }^{d}$ Department of General Surgical \\ Science, Gunma University Graduate School of Medicine, Maebashi, Japan
}

\section{Key Words}

Ectopic sebaceous glands · Esophagus · Endoscopy · Follow-up

\begin{abstract}
Sebaceous glands in the esophagus are rare and are of particular interest because of their as yet unknown origin. We report a case with ectopic sebaceous glands diagnosed by esophageal endoscopy and biopsy, with follow-up endoscopic examinations for 3 years. Few cases with follow-up endoscopic findings have been reported. In our case, there were no significant overall changes during 3 years of follow-up, but the lesions fluctuated over time. While taking the endoscopic findings of the present or past cases into account, we discuss the possible pathogenic mechanisms of this condition.
\end{abstract}

\section{Introduction}

Sebaceous glands generally arise in close association with hair follicles to form the pilosebaceous apparatus, but they are also found independently. Sebaceous glands are unevenly distributed over the body surface, being most numerous on the face and scalp, less numerous over the thorax and abdomen, and sparest on the extremities [1].

Ectopic sebaceous glands, consisting of small yellow nodules of the lips and oral cavity (Fordyce's spots), were first described in 1896 [2]. Many otherwise healthy persons were found to have Fordyce's spots, so that they are no longer considered a rarity or a disease entity. Then the lesions have been recognized in many tissues of ectodermal origin including salivary glands, prepuce and vulva. In the esophagus, 
which is derived from endoderm, ectopic sebaceous glands are rare. Ectopic sebaceous glands in the esophagus were first reported in autopsy cases microscopically [3], and the lesions were observed grossly in one autopsy case [4]. Recently, this condition diagnosed by esophageal endoscopy and biopsy has been reported in several living individuals $[5,6]$.

We report a case with ectopic sebaceous glands diagnosed by endoscopy and biopsy, and with yearly follow-up endoscopy for 3 years. There are few reports with detailed follow-up endoscopy over several years [5-7].

\section{Case Report}

An asymptomatic 56-year-old Japanese man visited our hospital in May 2008 for a routine medical examination, including upper gastrointestinal endoscopy. He had no obvious clinical signs and symptoms. He was a smoker and a social drinker. Blood tests showed a slightly elevated total cholesterol level of $263 \mathrm{mg} / \mathrm{dl}$, although other tests were within normal limits. He performed a diet cure because of mild hyperlipidemia.

Endoscopic examination revealed more than 100 yellowish plaques 1-20 $\mathrm{mm}$ in diameter scattered over the mucosal surface of the middle and lower thoracic esophagus ( $\underline{\text { fig. } 1 \mathrm{a}}$ ). The smaller lesions had a fine, granular appearance and the larger lesions had lobulated margins, giving them a flower-like appearance. Biopsy specimens stained with hematoxylin-eosin (H\&E) showed sebaceous glands associated with lymphocytic infiltration and an excretory duct, and overlying squamous epithelium (fig. 2). No evidence of hair follicles or malignancy was noted.

Repeat endoscopic examination at 1 and 2 years revealed that the lesions had decrease slightly in size or number compared with the first examination (fig. 1b, c). Sebaceous glands were still detectable on biopsy specimens. Endoscopic examination at 3 years revealed that the lesions had increased slightly in size or number compared with the preceding two examinations, to resemble the first endoscopy (fig. 1d). Overall, there were no significant changes in endoscopy findings over the 3 years. The patient continues to be followed up without treatment.

\section{Discussion}

Sebaceous glands are only rarely observed in the esophageal mucosa. Recently, several cases diagnosed by endoscopy and biopsy have been reported $[5,6]$. The apparently low incidence of this condition may be due to the lack of obvious clinical signs and symptoms. Most cases were discovered incidentally by endoscopy during a routine medical examination or at an annual follow-up examination [6]. The lesions in our patient were discovered incidentally during a routine medical examination. The patient was asymptomatic, and he was a smoker and a social drinker with mild hyperlipidemia. There is very limited evidence in the literature to support a possible pathogenic role of smoking, drinking or hyperlipidemia in this condition [5, 7].

Hoshika et al. [8] showed that patients with this condition typically have $<10$ lesions and that lesions are typically $>1 \mathrm{~mm}$ in size. Wei et al. [9] indicated that the number of lesions varied from 1 to more than 100 in one patient, with a diameter of 1-20 mm. Several studies have indicated that the lesions may have several different shapes, such as elevated form and lobulated plaque form $[9,10]$. The lesions were found predominantly in the upper thoracic esophagus, or mostly in the middle and lower thoracic esophagus [8-10]. In our case, the patient had more than 100 lesions of 
lobulated plaque form measuring 1-20 $\mathrm{mm}$ in diameter in the middle and lower thoracic esophagus. Hoshika et al. [8] further reported cases with a longitudinal distribution of lesions and postulated that the distribution of sebaceous glands in the esophagus may be significant. However, there are little data to support this theory to date. In our patient, the lesions were distributed in a scattered pattern. The factors affecting the pattern and distribution of sebaceous glands in the esophagus require further study.

There are few reports of these lesions that include detailed follow-up endoscopic findings over several years [5-7]. Follow-up examinations are recommended at intervals of 6-12 months. In most cases reported to date, follow-up did not show any change in the size or number of lesions [6]. No malignant change arising from such ectopic lesions has been reported, suggesting a favorable prognosis [5]. Most patients with this condition will therefore not need treatment. In our case, follow-up endoscopic examination was repeated once a year for 3 years. The lesions fluctuated over the 3 years, but there were no obvious overall changes in size or number and no treatment was needed.

Whether sebaceous glands in the esophagus are truly ectopic or metaplastic is a point of greatest interest, as the esophagus originates mostly from the endodermal layer. It is possible that these glands are a congenital anomaly. However, this condition has not been described in children, even in large necropsy studies [11]. Thus, metaplasia of pluripotent cells in the endoderm layer is more likely. The esophagus is known to contain mucous glands reminiscent of salivary glands. Sebaceous glands have been found in salivary glands and have been attributed to metaplasia (acquired differentiation). It would therefore not be surprising for some of the numerous esophageal gland lobules to undergo sebaceous metaplasia. In the present case, there were no obvious changes but some fluctuations in appearance on endoscopic examination over 3 years. It is unknown whether these endoscopic findings participate with the origin of sebaceous glands in the esophagus. However, further research is needed to clarify the mechanisms underlying the development of ectopic sebaceous glands in the esophagus.

\section{Disclosure Statement}

The authors have no conflicts of interest. 


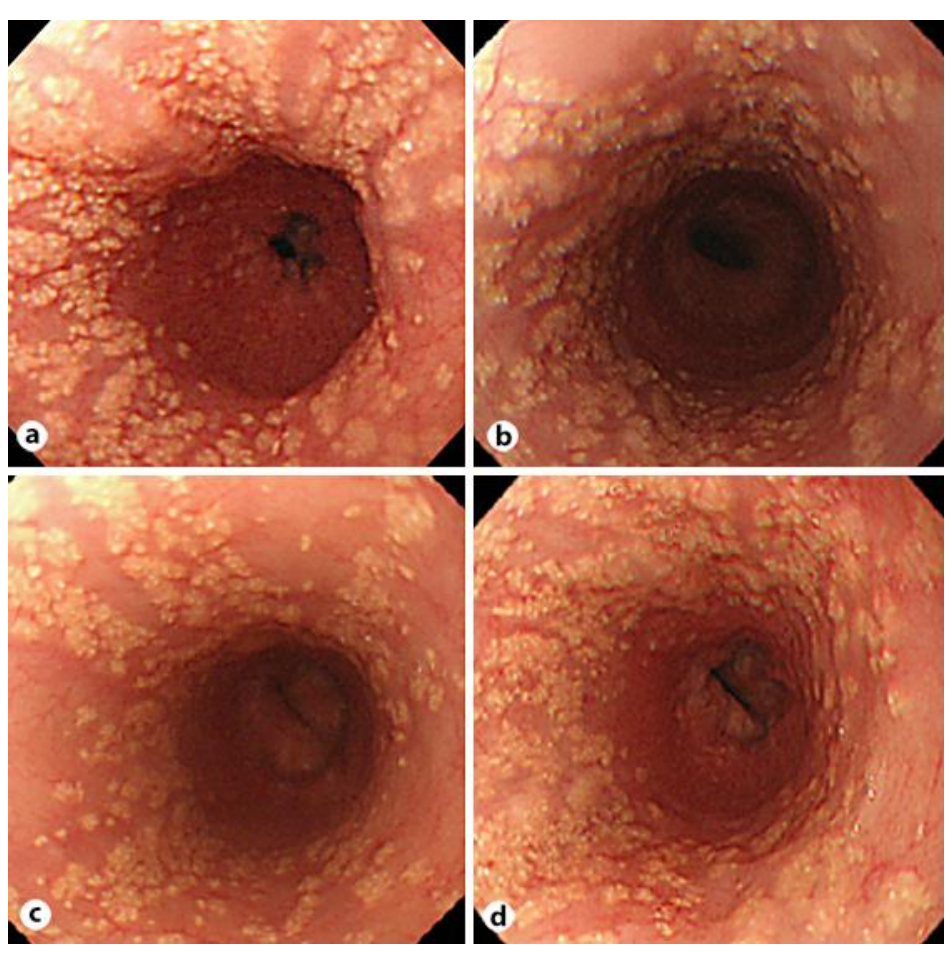

Fig. 1. Endoscopic examination. a First endoscopic examination: More than 100 yellowish plaques measuring 1-20 $\mathrm{mm}$ in diameter were seen in the middle and lower thoracic esophagus. The lobulated flower-like lesions were scattered over the mucosal surface. b Endoscopic examination after 1 year: The lesions had decreased slightly in size or number compared with the first examination. c Endoscopic examination after 2 years: The lesions had decreased further in size or number compared with the first examination. $\mathbf{d}$ Endoscopic examination after 3 years: The lesions had increased in size or number again and were similar to the first examination. 


\begin{tabular}{r|l|l|l}
$\begin{array}{r}\text { Case Reports in } \\
\text { Gastroenterology }\end{array}$ & $\begin{array}{l}\text { Case Rep Gastroenterol 2012;6:217-222 } \\
\text { DOI: 10.1159/000338651 }\end{array}$ & $\begin{array}{l}\text { Published online: } \\
\text { April 30, 2012 }\end{array}$ & $\begin{array}{l}\text { @ 2012 S. Karger AG, Basel } \\
\text { ISSN 1662-0631 } \\
\text { www.karger.com/crg }\end{array}$ \\
\hline
\end{tabular}

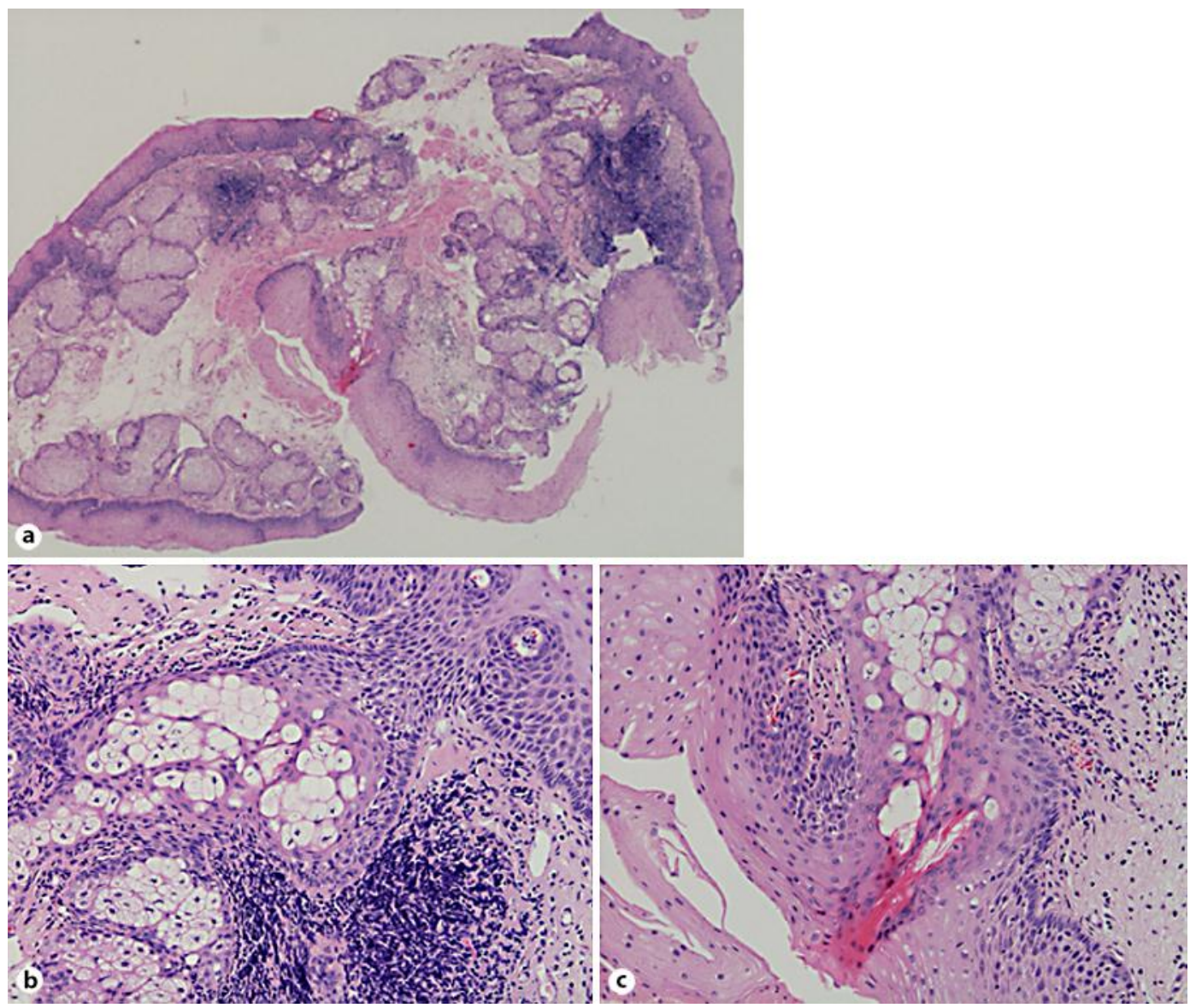

Fig. 2. Microscopic examination. a Squamous epithelium overlying the sebaceous glands $(H \& E, \times 10)$. b Lymphocytic infiltration is seen around the sebaceous glands $(\mathrm{H} \& \mathrm{E}, \times 100)$. c The excretory duct of a sebaceous gland is connected with the squamous epithelium $(H \& E, \times 100)$.

\section{References}

1 Guiducci AA, Hyman AB: Ectopic sebaceous glands. A review of the literature regarding their occurrence, histology and embryonic relationships. Dermatologica 1962;125:44-63.

2 Fordyce JA: A peculiar affection of the mucous membrane of the lips and oral cavity. J Cutan Dis 1896;14: 413-419.

-3 De La Pava S, Pickren JW: Ectopic sebaceous glands in the esophagus. Arch Pathol 1962;73:397-399.

-4 Zak FG, Lawson W: Sebaceous glands in the esophagus: first case observed grossly. Arch Dermatol 1976;112:1153-1154.

5 Nishisaki H, Yasutake K, Nakashima T, Hasegawa H, Hirohata S, Horita K, Sano W: Five cases with ectopic sebaceous glands. Dig Endosc 1997;9:207-212.

-6 Wang WP, Wang WS, Tsai YC: Multiple tiny ectopic sebaceous glands discovered throughout entire esophageal tract. Dig Dis Sci 2009;54:2754-2757.

7 Bertoni G, Sassatelli R, Nigrisoli E, Conigliaro R, Bedogni G: Ectopic sebaceous glands in the esophagus: report of three new cases and review of the literature. Am J Gastroenterol 1994;89:1884-1887.

-8 Hoshika K, Inoue S, Mizuno M, Iida M, Shimizu M: Endoscopic detection of ectopic multiple minute sebaceous glands in the esophagus. Report of a case and review of the literature. Dig Dis Sci 1995;40: 287-290. 
9 Wei IF, Chang CC, Fang CL, Hsieh CR, Wang JJ, Lou HY, Cheng T: Education and imaging. Gastrointestinal: ectopic sebaceous glands in the esophagus. J Gastroenterol Hepatol 2008;23:338.

10 Harada A, Tatsumi Y, Matsumoto T, Tani T, Nishida H, Katsura K: Ectopic sebaceous glands. Gastrointest Endosc 2004;60:97.

11 Rector LF, Connerley ML: Aberrant mucosa in the esophagus in infants and in children. Arch Pathol 1941;31:285-294. 